\title{
Study on Industrial Structure Optimization of Shaanxi Province Based on Improved Genetic Algorithm
}

\author{
Qunwei Wang \\ School of Automation \\ Northwestern Polytechnical University \\ Xi'an, China, 710072
}

\author{
Gangqiang Zha \\ School of Automation \\ Northwestern Polytechnical University \\ Xi'an, China, 710072
}

\author{
Shouzhi Xi \\ School of Automation \\ Northwestern Polytechnical University \\ Xi'an, China, 710072
}

\begin{abstract}
The adjustment and optimization of industrial structure are hot and difficult topics nowadays. In this paper, the improved Genetic Algorithm has been proposed to obtain the optimal value of multivariate function and that has been used to investigate the model of current industrial structure in Shaanxi Province. The results show that further optimization is needed for the current industrial structure adjustments in Shaanxi Province. After optimization, the industrial structure is more reasonable, the output scale is larger and second industry increase faster. The direction of recent adjustment of industrial structure in Shaanxi Province has also been guided by the improved Genetic Algorithm. It suggested that we should mainly develop the second industry, accelerate the development of tertiary industry and make development of the primary industry stably.
\end{abstract}

Keywords-gray system; Genetic Algorithm; industrial structure; optimization model

\section{INTRODUCTION}

The optimization of industrial structure is a process which from the lower stage to the advanced stage. In this process, the industrial structure not only has the updating form, widening of the industrial interface, but also the deepening and integrating development inter-industry. It also includes the sequence changes of input-output ratio, orderly variation in the internal structure of industry, optimization and development to a higher level, and it will gradually form a new industrial structure that beneficial to economic and social development. Through the development of relevant macro-industrial policies, government departments adjust the supply and demand of industrial structure to achieve optimal allocation of resources, which promote the development of the industrial structure to the advanced and reasonable direction.

In this paper, the industrial structure optimization model of Shaanxi Province is established by using gray system theory, and an improved Genetic Algorithm is proposed. The

Science and Technology Department of Shaanxi Province Key Project of Soft Science in Shaanxi Province: Development of Modern Service Industry in Shaanxi Province 2014KRZ02. optimal solution of industrial structure model of Shaanxi Province is obtained by improved Genetic Algorithm. By comparing with the actual value, it shows that the optimized value is better than the actual one, and the adjustment of industrial input structure in Shaanxi Province will bring more output and give the direction of industrial development in recent years.

\section{THE ESTABLISHMENT OF INDUSTRIAL STRUCTURE OPTIMIZATION MODEL}

\section{A. Determining the Model Coefficients}

Accurate forecasting is the premise and foundation of scientific decision-making. The traditional forecasting methods should be based on the large sample data. In fact, in scientific research, especially in the study of social and economic system, the greatest difficulty people often encountered is to obtain real and accurate data, which is also the biggest bottleneck in the research work, and the large sample conditions restrict the role of the traditional forecast methods in a certain extent. The gray system theory can be used to predict and study the economic system with incomplete information. This paper establishes the optimization model of the industrial structure of Shaanxi by using the gray system theory. Gray GM $(1,1)$ model is one of the most widely used models in the gray model group. The gray GM $(1,1)$ model emphasizes that modeling with small sample data can solve the problem that lack of data and cannot be forecasted by using the statistical model. The gray GM $(1,1)$ model develops and extracts valuable information from partial known information through the generation operation of the sequence, and realizes the correct description and effective monitoring of the system behavior. The essence of this model is to change the original sequence to a new sequence through constructing the mapping and to fit the new sequence with a curve and restored it to the original sequence[1]. 
According to the statistical data of Shaanxi Province from 2006 to 2013, the GM $(1,1)$ model is used to forecast the input system of industrial structure. The labor force, input coefficient, fixed asset investment, input coefficient, comprehensive energy consumption and input coefficient are obtained respectively, as shown in "Table I".

TABLE I. Related Data AND Forecast VAlue of InPUT System in ShaAnXi Province In 2014

\begin{tabular}{|c|c|c|c|}
\hline Name & Value & Name & Value \\
\hline $\begin{array}{c}\text { Total employment } \\
(10,000 \text { people })\end{array}$ & 2077.41 & $\begin{array}{l}\text { Investment coefficient of the second industry } \\
\text { ( } 100 \text { million yuan / } 100 \text { million yuan })\end{array}$ & 0.660241 \\
\hline $\begin{array}{l}\text { Employment coefficient of the first industry } \\
(10,000 \text { people / } 100 \text { million yuan })\end{array}$ & 0.398404 & $\begin{array}{l}\text { Investment coefficient of the third industry } \\
\text { ( } 100 \text { million yuan / } 100 \text { million yuan })\end{array}$ & 1.770285 \\
\hline $\begin{array}{l}\text { Employment coefficient of the second industry } \\
(10,000 \text { people / } 100 \text { million yuan })\end{array}$ & 0.063827 & $\begin{array}{l}\text { Comprehensive energy consumption } \\
(10,000 \text { tons of standard coal })\end{array}$ & 11917.15 \\
\hline $\begin{array}{l}\text { Employment coefficient of the third industry } \\
\text { ( } 10,000 \text { people / } 100 \text { million yuan })\end{array}$ & 0.093097 & $\begin{array}{l}\text { Energy consumption coefficient of the first industry } \\
(10,000 \text { tons / } 100 \text { million yuan) }\end{array}$ & 0.131995 \\
\hline $\begin{array}{l}\text { Investment in fixed assets } \\
(100 \text { million yuan })\end{array}$ & 18782.64 & $\begin{array}{l}\text { Energy consumption coefficient of the second } \\
\text { Industry ( } 10,000 \text { tons / } 100 \text { million yuan })\end{array}$ & 0.670771 \\
\hline $\begin{array}{l}\text { Investment coefficient of the first industry ( } 100 \text { million } \\
\text { yuan / } 100 \text { million yuan) }\end{array}$ & 0.816825 & $\begin{array}{l}\text { Energy consumption coefficient of the third industry } \\
(10,000 \text { tons / } 100 \text { million yuan) }\end{array}$ & 0.582273 \\
\hline
\end{tabular}

\section{B. Establishment the Model}

The development of the industry is mainly composed by the flow of labor, fixed assets investment, energy, natural resources, scientific and technological progress et.al. Due to uneasy calculation of the contribution of scientific and technological progress in various industries and quantification, this paper does not consider the role of scientific and technological progress in various industries in the establishment of the model. According to the available statistical data, this paper chooses labor, fixed assets investment, energy consumption and other factors as constraints to establish the gray dynamic linear programming model, and then analyzes the optimization of industrial structure in Shaanxi province.

Set: $\mathrm{x} 1 、 \mathrm{x} 2 、 \mathrm{x} 3$ denote the gross domestic product (GDP) of the first, second and third industries, respectively, in Shaanxi Province (100 million yuan). b1 represents the labor input (10,000 people); b2 represents fixed asset investment (100 million yuan); b3 represents the comprehensive energy consumption (10,000 tons of standard coal). The a11, a12, a13 represent the required amount of labor of the first, second and the third industry GDP $(10,000$ people / 100 million yuan) in Shaanxi province. The a21, a22, a23 represent the required investment in fixed assets of the first, second and the third industry GDP (100 million yuan / 100 million yuan) in Shaanxi province. The a31, a32, a33 represent the required comprehensive energy consumption of the first, second and the third industry GDP (10,000 people / 100 million yuan) respectively[2] [3] [4].

The gray dynamic linear programming model of Shaanxi Province in 2014 is obtained from the forecast data of "Table I":

$$
\operatorname{maxG}_{2014}=x_{1}+x_{2}+x_{3}
$$

The constraint conditions for $x_{1}, x_{2} 、 x_{3}$ are:

$$
\left\{\begin{array}{c}
0.398404 x_{1}+0.063827 x_{2}+0.093097 x_{3} \leq 2077.41 \\
0.816825 x_{1}+0.660241 x_{2}+1.770285 x_{3} \leq 18782.64 \\
0.131995 x_{1}+0.670771 x_{2}+0.582273 x_{3} \leq 11917.15 \\
x_{1}, x_{2}, x_{3} \geq 0
\end{array}\right.
$$

\section{THE IMPROVED GENETIC ALGORITHM}

\section{A. Generation of Genetic Algorithm}

Genetic Algorithms (referred to as GA) originated from the computer simulation study of the biological system, which is created by Professor JohnH.Holland of the University of Michigan. Genetic Algorithm is a stochastic global search and optimization method which imitates the evolution mechanism of natural biological evolution, and it draws lessons from Darwin's theory about evolution and Mendel's theory about heredity. It is a kind of efficient, parallel, global search method, which can obtain and accumulate related knowledge of the search space automatically, and can control the search process to obtain the optimal solution. In each generation of the Genetic Algorithm, a new approximate solution is generated according to the fitness value of the individual in the problem domain and the reconstruction method which is used for reference in the natural inheritance. This process leads to the evolution of the individuals in the population, and the new individuals are more adaptable to the environment than the original individuals, just as they are in nature reformation. The Genetic Algorithm as a new global optimization search algorithm, with the simple, general, robust, suitable for parallel processing and other significant features, has laid a strong position as one of the intelligent optimization algorithms in twenty-first Century. Therefore, the Genetic Algorithm is widely used in automatic control, computer science, pattern recognition, engineering design, intelligent fault diagnosis, management science and social science fields, which is suitable for solving complex nonlinear and multidimensional optimization problems.

Although the Genetic Algorithm has many advantages, there are still some unsatisfactory aspects in actual application, such as premature convergence, poor local search ability, low efficiency, and setting problems in 
controlling parameter. In some improved Genetic Algorithm, the improved three operators are usually the crossover operation in the Genetic Algorithm, and the single point crossover operation are randomly selected from two chromosomes, taking a point in the "family" of ancestors with high fitness patterns, but this approach has one-sided characterization. It is proved that the simple Genetic Algorithm is not convergent in any case, that is, the global optimal solution can not be searched. And through the improved Genetic Algorithm, that is, preserving the current optimal solution before (or after) the selection, it can guarantee convergence to the global optimal solution. Although it has been proved that the improved Genetic Algorithm can converge to the optimal solution, the time required to converge to the optimal solution may be longer. In addition, the premature problem is a phenomenon that can not be ignored in the Genetic Algorithm, all the individuals in the population reach the same extreme and stop the evolution. The individual closed to the optimal solution is always eliminated, and the evolutionary process is not convergent.

\section{B. The improved Genetic Algorithm}

In order to solve some problems in Genetic Algorithm, the following methods is used in this paper to solve the problem:

- To determine the probability of mutation dynamically. It can prevent the destruction of good genes due to the variation and introduce new genes into the population when they fall into the local optimal solution;

- To improve the selection method and the roulette wheel selection. It can avoid the stop of population evolution due to little difference because the early high fitness individuals quickly occupied the population and the latter part of the population; Roulette wheel selection method will make each individual get a copy of the opportunity, and that can't reflect the competitiveness of individuals and achieve the principle of Genetic Algorithm survival of the fittest. In view of this, a selection algorithm based on the population according to the sorting of the individual fitness is used and is added in the wheel selection method.

Based on the above analysis, the improved Genetic Algorithm can be described as follows:

- In the initial population, all the individuals are ranked according to their fitness, and then the support and confidence of the individuals are calculated;

- Replication according to a certain proportion (that is, the two individuals with the highest fitness in the current population are copied into the population to be matched);

- Determine their mutation probability and start variation according to the position of the individual;
- Stop if the end condition is satisfied. Otherwise, skip to step 1 until all the matching rules are found.

The advantage of this algorithm is that during every evolution of each generation, the offspring always retain the best individuals in their parents to search for better samples in the "high fitness mode for ancestor family direction". Thereby ensure the global optimal solution can be searched. The implementation process of Genetic Algorithm is shown in "Fig. 1".

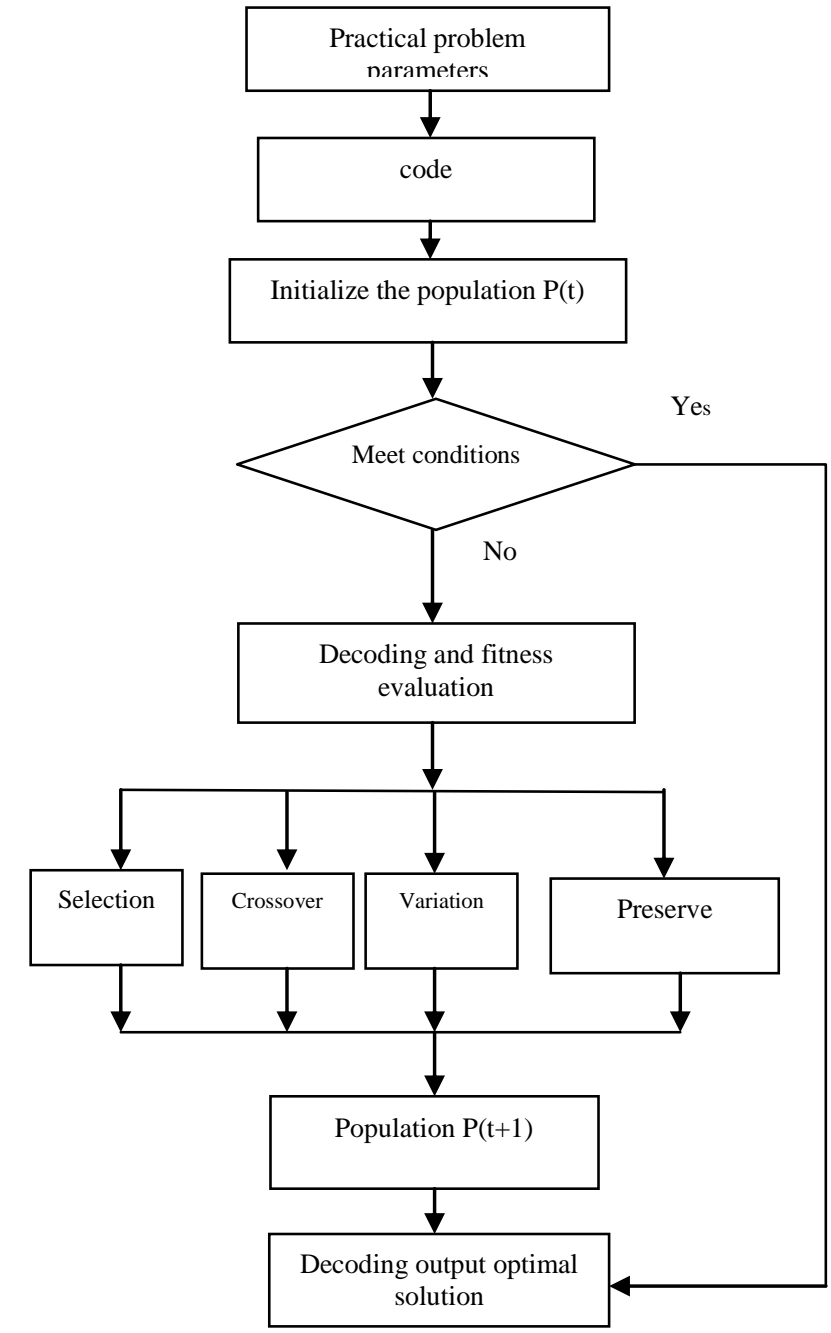

Fig. 1. The diagram of Genetic Algorithm implementation process

\section{OPTIMAL SOLUTION TO THE MODEL}

\section{A. Determine the Parameter Range}

According to the objectives of economic development planning of Shaanxi Province, combined with the new circumstance of economy development in recent years, the minimum is based on 2013 and the maximum value is based on the industry growth rate increased 15 percentage of 2013 , then it can get the 2014 first, second and third production range : 


$$
\left\{\begin{array}{l}
1526 \leq x_{1} \leq 1632 \\
8911 \leq x_{2} \leq 10248 \\
5607 \leq x_{3} \leq 6495
\end{array}\right.
$$

Based on the improved Genetic Algorithm, the gray dynamic linear programming model of Shaanxi Province in 2014 is programmed to solve the optimal value by using MATLAB7.1. Programming ideas:

- According to the upper and lower boundary difference of a given solution accuracy, it can obtain a single variable encoding length by coding function,

- Using random function to generate $\mathrm{n}$ binary code length of three variable length as an individual of the initial population;

- $\mathrm{x} 1, \mathrm{x} 2$, and $\mathrm{x} 3$ are obtained by decoding the binary code of the individual, and the function value is obtained by substituting the objective function. According to the ratio of the distance between the function value and the maximum value of all the function values of the present generation to the sum of the distance of all individuals as fitness, the accumulation fitness constitutes a roulette wheel, that is, in the area of a betting round, the smaller the value of the individual is, the probability selected is greater. Meantime, it should improve the basic Genetic Algorithm and retain optimal value among each generation, then the binary code should pass to the next generation;
- Perform the selection function and select $\mathrm{n}$ new individuals as the new population by using the gambling wheel;

- Perform a crossover function and select an individual when the generated random number is smaller than the crossover probability, then generate a position of the selected two individuals randomly as an intersection point and exchange the code behind it;

- Perform variation function when the random number is less than the mutation probability and select an individual, then generate a position randomly as a variation point and set the encoding of the point to 1 (if the original is 0 ) or 0 (if the original is 1 );

- Repeat the implementation of decoding, seeking fitness, selection, crossover and changing several steps until $\mathrm{N}$-generation evolution is completed;

- In the final population, the smallest individual of the function value is chosen as the final individual, and the function value is the final optimized value.

\section{B. Result Analysis}

According to the solving steps of the improved Genetic Algorithm, the iteration number is 100, the crossover probability is 0.4 and the mutation probability is 0.05 . Five groups are executed after 5 times performance, the average value of each variable and the objective function are obtained as the optimization of the industrial structure. The results are shown in "Table II".

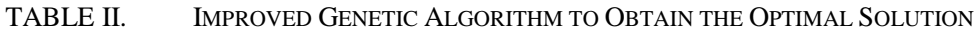

\begin{tabular}{|l|l|l|l|l|l|l|}
\hline & the first time & the second time & the third time & the fourth time & the fifth time & the sixth time \\
\hline $\mathrm{fmax}$ & 1816.7 & 18040 & 18110 & 18159 & 18122 & 18119.6 \\
\hline $\mathrm{X}_{1}$ & 1591 & 1591 & 1592 & 1591 & 1592 & 1591.4 \\
\hline $\mathrm{X}_{2}$ & 10086 & 10069 & 10073 & 10080 & 10071 & 10075.8 \\
\hline $\mathrm{X}_{3}$ & 6490 & 6380 & 6445 & 6488 & 6459 & 6452.4 \\
\hline
\end{tabular}

As can be seen in "Table II", the optimal GDP in 2014 is 1811.96 billion yuan. The added value of the primary industry is 159.14 billion yuan. The added value of the secondary industry is 1007.58 billion yuan. The added value of the tertiary industry is 645.24 billion yuan. The ratio of the three industries is 8.78: 55.61: 35.61 .

In 2014, the actual GDP of Shaanxi Province is $1,768.994$ billion yuan. The added value of the primary industry was 156.494 billion yuan. The secondary industry is
969.878 billion yuan and the tertiary industry was 643.522 billion yuan.

As can be seen in "Table III", the forecast of the optimal GDP is higher than the real GDP, and there is larger increase in the secondary industry. It indicates that the current industrial structure in Shaanxi is not optimal. It can get more output only take a little adjustment. The secondary industry still should be mainly developed in the near future.

TABLE III. 2014 Optimized AND ACtUAL VALUES UNIT: 100 MiLlion YUAN

\begin{tabular}{|l|l|l|l|l|}
\hline & Gross product & $\begin{array}{c}\text { Added value of primary } \\
\text { industry }\end{array}$ & $\begin{array}{c}\text { Added value of } \\
\text { secondary industry }\end{array}$ & $\begin{array}{c}\text { Added value of the tertiary } \\
\text { industry }\end{array}$ \\
\hline Predicted optimal value & 18119.6 & 1591.4 & 10075.8 & 6452.4 \\
\hline Actual value & 17689.94 & 1564.94 & 9689.78 & 6435.22 \\
\hline
\end{tabular}

\section{CONCLUSION}

This paper introduces the realization process and programming idea of the improved Genetic Algorithm. The gray system theory is used to establish the gray system industrial structure adjustment model in Shaanxi Province. The improved Genetic Algorithm is used to solve the optimal solution of the model. After years of development, the industrial structure in Shaanxi Province tend to rationalize, but the key development industrial is still the second industry. During the 13th Five-Year Plan period, the industrial structure which developed by both two and three industry will form. With the development of economy, the proportion of the tertiary industry will surpass the second industry to 
become the biggest industry of Shaanxi's economic development.

\section{REFERENCES}

[1] Sifeng Liu, NaimingXie et al. The application and principle of gray system. (Sixth Edition) [M]. Science Press, Beijing, Jun. 2013.

[2] The study of several basic form and its application scope of G, M (1,1) models [J]. Systems Engineering and Electronics. 2014(3): P501-508.

[3] Mingxia Cao. Optimization model and empirical analysis of industrial structure adjustment of Nanjing [J]. Statistics and Decision, 2008(3): P117-119.

[4] Yaoguo Dang, Sifeng Liu, Qingfeng Wang. Theory and practice of Regional industrial structure optimization [M]. Science Press, Beijing, May 2011.

[5] Yingjie Lei, Shanwen Zhang et al. The application and basic theory of MATLAB Genetic Algorithm[M]. Xidian University Press, Xi'an, Feb. 2014.

[6] Minqiang Li, Jisong Kou, Dan Lin, Shuquan Li. The application and basic theory of Genetic Algorithm[M]. Science Press, Beijing, Jan. 2002 